\title{
De dynamiek van een migratiereis van Afrika naar Europa
}

\section{J. Schapendonk*}

Nadat in de eerste vier maanden van 2015 een geschat aantal van 1.750 migranten verdronken is in de Middellandse Zee, zijn de EU-landen met spoed bijeengekomen om een gezamenlijk actieplan te ontwikkelen tegen de aanhoudende ongewenste migratie uit delen van Azië en Afrika. Het tienpuntenplan dat het resultaat was van het spoedberaad illustreert dat de Europese Unie (EU) irreguliere migratie vooral ziet als een gezamenlijk veiligheidsprobleem. Om Europa te 'beschermen' tegen onwelkome migranten wordt meer geld vrijgemaakt voor grensbewakingsoperaties van Frontex (Triton en Poseidon), worden militaire middelen niet geschuwd om smokkelnetwerken te ontregelen en wordt zowel op Europees niveau (tussen politie, justitie en Frontex) als op intercontinentaal niveau (tussen EU en respectievelijk Libië en Niger) ingezet op betere institutionele samenwerking om potentiële kandidaten voor de oversteek een halt toe te roepen. Het is tekenend dat een verdeling van asielzoekers over de lidstaten - ook een element van het tienpuntenplan - als meest controversieel werd gezien, en later 'on hold' werd gezet door de ministers van Justitie. Een verdere securisation of migration (Nyberg-Sørensen 2012; Andersson 2014) lijkt het voornaamste Europese antwoord op de recente drama's op de Middellandse Zee.

Zoals meerdere migratiedeskundigen onderstrepen, zal een steeds restrictiever migratiebeleid eerder de smokkelmarkt een impuls geven dan dat het een gepaste oplossing biedt voor de gevaarlijke migratiereizen. Immers, hoe moeilijker het is voor een migrant om een grens over te steken, des te eerder zal hij of zij nadenken over welke assistentie nodig is om een gewenste bestemming te bereiken. Zo stelt Hein de Haas dat smokkel onterecht als oorzaak van migratie wordt gezien, daar het juist een reactie is op restrictief migratiebeleid (De Haas 2015). Ook is de kans groot dat een verdere securisation of migration

* Dr. Joris Schapendonk is verbonden aan de Faculteit Geografie, Planologie en Milieu van de Radboud Universiteit te Nijmegen. 
een van de belangrijkste uitgangspunten van het hedendaagse beleid - het ontrafelen van een mixed flow door de 'echte vluchteling' te onderscheiden van 'de gelukzoeker' - verder zal problematiseren. Omdat andere kanalen ontbreken om Europa veilig te bereiken zijn Syrische en Eritrese vluchtelingen gedwongen zich te gedragen als irreguliere migranten door ongezien en ongevraagd de Europese grens over te steken. Tegelijkertijd zullen migranten met overwegend economische motieven uit bijvoorbeeld Nigeria of Gambia zich blijven melden in asielprocedures omdat dit een van de weinige kanalen is om uiteindelijk legaal in Europa te verblijven. Kortom, als er niet nagedacht wordt over het openstellen van meer reguliere migratiekanalen, dan zal het voorgestelde Europese beleid ineffectief zijn, zo stellen verschillende migratiedeskundigen. ${ }^{1}$

Het is bij deze beleidsdiscussies belangrijk in te zien dat de migrant of vluchteling in het huidige publieke discours niet alleen wordt afgeschilderd als onwelkome indringer, maar doorgaans ook als een passief slachtoffer van transnationale smokkelnetwerken die de migrant volledig in hun macht hebben. Dit beeld is om ten minste drie redenen misleidend. Allereerst geeft het een eenzijdig beeld over de relaties tussen reisagenten en migranten. De organisatiestructuur en verhoudingen tussen actoren verschillen sterk. De migrant heeft in veel gevallen wel degelijk zeggenschap over de richting van de reis, en de wijze waarop de bestemming bereikt wordt (Van Liempt 2007; Khosravi 2011). De smokkelaar die gewapend een migrant een bootje op jaagt, is er slechts één uit een breed pallet aan migratiediensten. Ten tweede heeft een dergelijke invulling weinig oog voor de niet-commerciële relaties die migratie mogelijk maken: deze variëren van familieen etnische relaties tot onbekenden die een helpende hand bieden (Schapendonk 2014). Ten slotte is het beeld van de georganiseerde mensensmokkel en de migrant als zijn slachtoffer veelal gebaseerd op slechts een gedeelte van de reis die migranten afleggen - namelijk de oversteek met de boot van bijvoorbeeld de Noord-Afrikaanse kust naar Italië of Malta. De migrant die door de woestijn reist, maakt in veel gevallen gebruik van lokaal of regionaal opererende netwerken (inclusief reguliere busmaatschappijen) en moet doorgaans zelf de verschillende passages aan elkaar verbinden. Maar belangrijker nog dan deze

1 Zie bijv. de mediaoptredens van Alexander Betts (2015), Leo Lucassen (geciteerd in Van Raaij 2015), Thomas Spijkerboer (2015), Henk van Houtum (2015), Hein de Haas (2015), Marieke van Houte \& Leonhard den Hertog (2015) en François Crépeau (2015). 
inhoudelijke nuancering is het feit dat de fixatie op de organisatie van de reis het zicht beneemt op de leefwereld van migranten. Met andere woorden, het idee is dat als we de wijze van reizen tegengaan, ook de wil en reden om te reizen onder potentiële migranten verdwijnen. Dit valt te betwijfelen.

Dit artikel zoomt in op slechts één migratietraject om de dynamiek van de reis te illustreren vanuit de ogen van de migrant. Echter, door het in detail volgen van zijn migratiereis stuiten we ook op de verhalen van medereizigers en kunnen we de verwachte en onverwachte uitkomsten van de ontmoeting tussen Afrikaanse aspiraties en Europese grenzen bediscussiëren (zie ook Schapendonk \& Steel 2014). Alvorens deze reis in detail te beschrijven, ga ik eerst dieper in op de vraag hoe migratieaspiraties ontstaan in West-Afrika.

\section{‘Destination Europe’}

Mijn onderzoek naar de trajecten van West-Afrikanen die op weg zijn naar Europa sluit aan bij een heel veld van kwalitatief onderzoek naar West-Afrikaanse leefwerelden aangaande internationale mobiliteit (zie bijv. Brachet 2005; Alpes 2011; Süter 2012; Lucht 2012; Andersson 2014). Waar ik voorheen (2007-2011) met name aandacht had voor Afrikaanse migratie naar, en door, de zogenoemde transitruimtes (Marokko en Turkije), richt ik me in mijn huidige onderzoek (2015-2018) op de intra-EU-mobiliteit van dezelfde groep migranten -, met een focus op migranten uit Senegal/Gambia en Nigeria. ${ }^{2}$ De verklaring van deze migratie ligt naar mijn indruk op het snijvlak van enerzijds structurele politiek-economische instabiliteit (zie bijv. Black e.a. 2004) en anderzijds alledaagse globaliseringsprocessen. Met betrekking tot het laatste zegt de Afrika-expert James Ferguson (2006) dat de crux vooral zit in het feit dat de jonge bevolking van Afrika in haar alledaagse bestaan wordt geconfronteerd met mondiale interacties, maar tegelijkertijd voelt de bevolking dat ze niet volwaardig deelneemt aan dezelfde mondiale samenleving. Het gebrek aan mogelijkheden om te migreren levert frustraties op (Carling 2002) - wat een verklaring kan bieden voor de vraag waarom jonge Afrikanen het pad van irreguliere migratie kiezen.

2 Dit project getiteld 'Fortress Europe as a mobile space?' wordt met een VENI-beurs gefinancierd door NWO. 
Het land Gambia is een illustratief voorbeeld voor het samenkomen van beide verklarende elementen. Het West-Afrikaanse land wordt niet zozeer geteisterd door gewelddadige conflicten, maar de bevolking gaat al wel meer dan twintig jaar gebukt onder het strenge bewind van president Jammeh. Enkele respondenten noemden hem 'the next Ghadaffi of Africa'. Ondanks dit regime is Gambia in WestEuropa vooral bekend als toeristenoord. Het dagelijkse contact met Europa, ${ }^{3}$ in combinatie met het onderdrukkende politieke bewind, is voor veel jongeren de reden om op weg te gaan naar 'Destination Europe'. Deze combinatie van politieke en sociaaleconomische factoren wordt in de literatuur aangeduid als mixed migration - een term die aangeeft dat het dichotome onderscheid tussen economische migrant versus politiek vluchteling in de praktijk vaak moeilijk te maken valt (Castles 2007; Papadopoulou 2005).

\section{Yayha's weg naar Europa}

Op een regenachtige dag in april (2014) ontmoet ik Yayha op een treinstation in de Italiaanse regio Liguria. Hij is een lange man, begin 30, en afkomstig uit Gambia. Hij omhelst me als een vriend - dit is niet geheel verwonderlijk omdat Yayha's oudere broer daadwerkelijk een goede bekende van mij is. Met zijn vertrek wilde Yayha in de voetsporen treden van zijn grote broer, die al enkele jaren met de juiste papieren in Europa verblijft. Hoewel in migratietheorieën vaak wordt gesteld dat familieleden in een bestemmingsland van invloed zijn op migratiebeslissingen, was Yayha's reis door de Sahara geheimgehouden voor zijn broer. Diens hulp werd pas ingeschakeld nadat Yayha Senegal, Mali en een groot deel van Niger had doorkruist. Bij een laatste checkpoint, net voor Agadez, hebben Nigerese autoriteiten het laatste geld van Yayha buit gemaakt door middel van dubieuze transit taxes. Dit impliceert dat naast de genoemde smokkelaars ook de autoriteiten deel uitmaken van de migration industry (Andersson 2014). Zoals twee vrienden van Yayha mij vertelden: 'They are making money from us. The drivers and the police officers, and the soldiers ... They are all the same mafia!' Het samensmelten van corrupte autoriteiten

3 Toerisme is slechts een van de factoren die deze connectiviteit bewerkstelligt. Andere belangrijke factoren zijn bijv. sociale media, consumptiegoederen en transnationale relaties met migranten die gevestigd zijn in de EU. 
en mensensmokkelaars is ook een bekend fenomeen op de route vanuit Oost-Afrika naar Libië (Triulzi \& McKenzie 2013).

Platzak in Agadez besluit Yayha zijn broer in te schakelen. Onaangenaam verrast met Yayha's gevaarlijke reis reageerde zijn broer uitermate kribbig op het verzoek om financiële hulp en hij weigerde in eerste instantie zijn medewerking. Pas na een paar weken kreeg Yayha van zijn broer alsnog een bedrag van enkele honderden euro's toegestuurd via Western Union. Maar zijn broer wist ook dat dit bedrag niet genoeg zou zijn voor een overtocht naar Europa. Hij vreesde dat Yayha in Libië opnieuw in de problemen zou komen. Om deze reden kocht hij een tweedehands Mercedes, en verscheepte deze na de nodige administratieve handelingen naar Banjul (de hoofdstad van Gambia). Hij 'verkocht' deze auto aan een Gambiaanse vrouw van wie bekend was dat haar man in Tripoli werkte als connection man - een tussenpersoon die migranten probeert te verzamelen voor een bootreis. Deze in Europa gekochte auto fungeerde als betaalmiddel voor Yayha's latere overtocht naar Italië.

\section{'Crossing the river'}

Op een ochtend werd Yayha met ongeveer honderd andere migranten verzameld en naar de kust buiten Tripoli gebracht. Daar moest hij enkele uren wachten voordat hun boot arriveerde. Het bleek een opblaasboot, steevast viber boat genoemd door mijn respondenten. Deze boot diende nog te worden opgeblazen door de potentiële passagiers en nog naar de vertrekplaats te worden gebracht. Om ongeveer elf uur's avonds waren alle voorbereidingen getroffen, en werden de reizigers in verschillende boten gedirigeerd. Er pasten zo'n dertig migranten in één viber boat. De passagiers in Yayha's boot waren allemaal West-Afrikaanse mannen, inclusief de kapitein. Zoals Hans Lucht (2012) beschrijft, wordt voor de oversteek vaak gebruik gemaakt van West-Afrikaanse migranten die enige ervaring hebben in het besturen van boten op open zee, zoals vissers. Dit werpt een bijzonder licht op het Europese idee boten te kunnen enteren om migratie tegen te gaan. Op dergelijke boten zullen weinig sporen te vinden zijn van Libische reisagenten, zoals een van mijn respondenten zei: 'We never see Libyans inside the boat to come over. They are not visible!' Tijdens 
een in mei 2015 gehouden seminar ${ }^{4}$ gaf een vertegenwoordiger van Frontex dan ook aan dat deze beoogde maatregel alleen kon gelden voor grotere vracht- en containerschepen.

Op een Italiaans strand liet Yayha mij meerdere foto's zien van viber boats en wees hij mij de exacte plek aan waar hij zat (dicht bij de rand, en redelijk voor in de punt). Op die plek heeft hij ongekende doodsangsten uitgestaan, die hij nu met een knikkend hoofd en een brede glimlach lijkt weg te wuiven. Na een volle nacht en een volle dag op zee verloor de boot de juiste koers. Gelukkig kwamen zij een commercieel schip uit Malta tegen. De bemanning voorzag de migranten van wat water en gaf de juiste koers door aan de migrant/kapitein en zijn assistent die het kompas bediende. Waarschijnlijk is het dezelfde bemanning die de Italiaanse autoriteiten heeft gewaarschuwd, want ongeveer vier uur later verscheen de Italiaanse kustwacht. De river crossing - zoals meerdere migranten de overtocht noemden - was voltooid. De bootpassagiers werden naar Lampedusa gebracht, van waaruit ze na enkele dagen naar respectievelijk Rome en een plek iets buiten Napels werden gestuurd. Daar verbleven de migranten ongeveer zes maanden voordat ze verspreid werden over meerdere locaties in het land.

\section{‘Paper lottery'}

De boottocht en de collectieve transfer van Lampedusa naar Napoli creëren een gezamenlijke ervaring die voor de migranten voor de nodige sociale verbinding zorgt. Soms worden vriendschappen gesloten tijdens de boottocht, in andere gevallen blijft men elkaar ondersteunen tijdens het verblijf in een van de centra die voor migranten zijn opgezet. Zo werd Yayha tijdens mijn bezoeken in april 2014 en mei 2015 telkens vergezeld door twee vrienden 'from the same boat', die ik ook steeds beter leerde kennen. Onderling worden de trajecten van comigranten nauwlettend in de gaten gehouden. Via Yayha en zijn vrienden kwam ik in contact met twee andere medepassagiers. Een van hen was naar Milaan gestuurd, de ander kon in Napels blijven. Laatstgenoemde locatie was verreweg het meest populair onder mijn

4 Dit seminar vond plaats op 27 mei 2015 in Utrecht en was georganiseerd door het Centre for Information and Research on Organised Crime (CIROC). 
respondenten, omdat Napels bekendstaat als een raba raba place, een plaats waar je snel toegang vindt tot de informele economie. In het algemeen hebben deze vijf jongens die met dezelfde boot aankwamen een vergelijkbare achtergrond qua motivatie, sociaaleconomische achtergrond en leeftijd (tussen 20 en 33 jaar). Vier van deze vrienden komen uit Gambia, een van hen komt uit buurland Senegal. Geen van hen heeft het land verlaten vanwege een voortdurend gewelddadig conflict, maar alle vijf beschreven ze de beperkte mogelijkheden in hun regio. Ondanks deze gelijkenissen zijn de verblijfsprocedures en perspectieven zeer uiteen gaan lopen tussen september 2013 en juni 2015. Yayha heeft een eenjarige hernieuwbare verblijfsvergunning gekregen op humanitaire gronden. Dit heeft hem onder zijn vrienden in het migratiecentrum de bijnaam Tycoon opgeleverd. Dit is een titel die normaal gesproken voorbehouden is voor migranten met een langdurig legaal verblijf in Italië, die hiermee in staat zijn andere migranten in huis te nemen (zie ook Lucht 2012). Of zijn verblijfsvergunning wordt verlengd, is afwachten. Het is bekend dat veel migranten in Italië schipperen tussen kortstondige verblijfsstatussen en periodes van ongedocumenteerdheid (Schuster 2005).

In tegenstelling tot Yayha zijn de aanvragen van zijn twee Gambiaanse vrienden die in hetzelfde centrum verblijven, geweigerd door de Italiaanse autoriteiten. Zij zijn in beroep gegaan en hopen dat de uitspraak over hun tweede aanvraag binnenkort komt. Op basis daarvan worden nieuwe plannen gemaakt, zoals de 21-jarige Omar aangaf:

'lk verwacht het besluit van de commissie erg snel. Dan zal ik beslissen wat ik zal doen. Als ze mij een document geven, dan zal ik blijven om te wachten tot een "stable paper" [verblijfsdocument geldig voor langere tijd; JS]. Als ik een negatief krijg, dan heb ik drie opties. Ik teken om terug te gaan naar mijn land, ik teken om hier in Italië te blijven [als ongedocumenteerde migrant; JS] of ik teken dat ik naar een ander Europees land ga. In dat geval zal ik naar een ander Europees land gaan.'

Waar Omar nog moet afwachten of hij überhaupt uitzicht heeft op een legaal verblijf in Italië, is er voor de enige Senegalees binnen dit sociale netwerk meer duidelijkheid. Hij heeft vanuit Napels namelijk direct een vluchtelingenstatus gekregen die gekoppeld is aan een vijfjarige verblijfsvergunning. Zijn leven lijkt, zoals hijzelf aangaf, zich voor de lange termijn in Zuid-Italië af te spelen. 
Saihou, de vijfde jongen uit dezelfde boot die ik heb geïnterviewd, heeft nog een ander pad bewandeld. Hij is vanuit Napels naar Milaan overgeplaatst. Maar na een negatief besluit van de commissie is hij naar Zwitserland gegaan om daar zijn geluk te beproeven. In de asielprocedure werd hij echter als Dublin-casus bestempeld. In plaats van deze terugkeerprocedure in te gaan, ging hij voor een aantal maanden underground in Zwitserland door bij zijn toenmalige Zwitserse vriendin te verblijven. Bij een reguliere controle op straat liep hij echter tegen de lamp en werd twee weken in detentie gezet. Van daaruit werd hij teruggebracht naar Italiaans grondgebied en besloot hij bezwaar te maken tegen zijn eerder afgewezen asielaanvraag. Hoewel zijn beroep niet kansloos is, is hij vastbesloten niet passief af te wachten wat het resultaat zal zijn. Want, zoals hij aangaf, je kunt nooit vertrouwen op een goede afloop - de asielprocedure is wat dat betreft net een loterij. Hoewel zijn Italiaanse procedure nog loopt, heeft Saihou begin juni 2015 het Italiaanse grondgebied met een personenauto verlaten.

\section{Conclusie}

Yayha is op zijn reis door de Sahara reeds vele grenzen tegengekomen. Enkele migranten deelden in dit kader hun ervaring in detentiecentra in Libië - een grensmaatregel die in het verleden mede door Europees geld is gefinancierd. Meerdere stemmen geven aan dat de toekomst van het Europese migratiebeleid ligt in het verder externaliseren van de Europese grens, wat neerkomt op opvang van vluchtelingen in de 'eigen' regio, en het verder ontmoedigen van diegenen die op reis zijn door goede samenwerkingsverbanden aan te gaan in zogenaamde transitlanden. Het is waarschijnlijk dat Yayha's opvolgers alleen nog maar meer begrenzingen tegenkomen in de nabije toekomst. Naast deze externalisering van het Europese migratiebeleid hebben we de werking (en niet-werking) van de interne Europese grenzen gezien toen Saihou eerst als Dublin-case werd bestempeld, maar niet werd uitgezet. Later gebeurde dit wel op basis van een onverwachte controle op straat. De migratiereis wordt in dat geval begrensd door het beheren van datasets (vingerafdrukken in het Eurodac-systeem) en het intern surveilleren van mobiliteit (Rumford 2006; Broeders 2007). Tegenover deze wereld van meer grenzen staan de 'grenzeloze' dynamiek van globaliseringsprocessen en de fluïde organisatie van migra- 
tiereizen. De auto die door Yayha's broer verscheept werd van Europa naar Gambia om Yayha's reis in Libië een vervolg te geven, is daarbij niet alleen een empirisch detail - het is een symbool dat de mobiliteit van personen tussen Afrika en Europe sterk verweven is met de grensoverschrijdende mobiliteit van kapitaal, informatie en goederen tussen dezelfde continenten. In deze transnationale realiteit trachten jonge Kameroeners (Alpes 2011), Nigerianen (Süter 2012), Ghanezen (Lucht 2012) en Senegalezen (De Clerck 2015) hun dromen te verwezenlijken. Het is daarbij een misvatting dat Afrikaanse migranten blind zijn voor de risico's die met migratie gepaard gaan (Alpes \& NybergSørenson 2015). Sommige van mijn respondenten zijn zelf getuige geweest van het overlijden van hun medereizigers. Via de wegen van globalisering krijgen zij echter allerlei succesverhalen te zien en te horen die opwegen tegen de mogelijke ontberingen op hun route. Verhalen over tragische ongevallen worden dan al snel vertaald in een extra motivatie om iets van je leven te maken (Andersson 2014). Een nieuwe Frontex-operatie en een nieuwe informatiecampagne zullen deze werkelijkheid naar alle waarschijnlijkheid niet veranderen. Minister Ploumen heeft het recentelijk over een andere boeg gegooid met haar brief in de Volkskrant (26 mei 2015), ${ }^{5}$ waarin ze terecht schreef dat deze migratie niet alleen door wanhoop wordt voortgedreven, maar eerder door lef en ambitie. Tevens deel ik haar inzicht dat er meer moet worden gedaan dan het 'onklaar maken van bootjes', en dat 'perspectief bieden' aan potentiële migranten een goed uitgangspunt is. De hamvraag is dan natuurlijk hoe dat perspectief bieden eruit moet zien ten tijde van globalisering. Wordt er louter ingespeeld op Europese belangen met het 'daar houden' van potentiële migranten, zoals Ploumen beoogt met het perspectief bieden 'in eigen land' door middel van ontwikkelingsinitiatieven? Of wordt de leefwereld van de Afrikanen ook meegenomen door na te denken over de vraag hoe deze mobiliteit kan worden gereguleerd? De geforceerde en paternalistische boodschap dat een jonge Gambiaan op zijn plek dient te blijven, terwijl hij zijn Europese spiegelbeeld de wereld ziet bereizen, zal hem waarschijnlijk niet overtuigen om de migratiedroom te laten varen.

5 'Kabinet geeft 50 miljoen aan Afrika om migratie te stoppen', de Volkskrant 26 mei 2015, www.volkskrant.nl/binnenland/kabinet-geeft-50-miljoen-aan-afrika-om-migratie-testoppen a4039890/. 


\section{Literatuur}

\section{Alpes 2011}

M.J. Alpes, Bushfalling. How young Cameroonians dare to migrate, Amsterdam: Universiteit van Amsterdam 2011.

\section{Alpes \& Nyberg-Sørenson 2015}

M.J. Alpes \& N. Nyberg-Sørenson, Migration risks campaigns are based on wrong assumptions (DIIS Policy Brief), Danish Institute For International Studies, mei 2015.

\section{Andersson 2014}

R. Andersson, Illegality, Inc. Clandestine migration and the business of bordering Europe, Oakland: University of California Press 2014.

\section{Betts 2015}

A. Betts, 'Why Europe's response to the Mediterranean crisis is disappointing', BBC World News 22 april 2015. Te raadplegen op:

www.rsc.ox.ac.uk/news/

alexander-betts-talks-to-the-bbcabout-the-eu2019s

-2018disappointing2019response-to-the-mediterraneancrisis?utm_source=twitterfeed \& utm_medium=twitter.

\section{Black e.a. 2004}

R. Black, S. Ammassari, S. Mouillesseaux \& R. Rajkotia, Migration and pro-poor policy in West Africa (Working Paper C8), Sussex Centre for Migration Research, november 2004. Te raadplegen op: www. migrationdrc.org/publications/ working_papers/WP-C8.pdf.

\section{Brachet 2005}

J. Brachet, 'Constructions of territoriality in the Sahara. The transformation of spaces of transit', Vienna Journal of African Studies (5) 2005, p. 239-253.

\section{Broeders 2007}

D. Broeders, 'The new digital borders of Europe. EU databases and the surveillance of irregular migrants', International Socio$\operatorname{logy}(22)$ 2007, afl. 1, p. 71-92.

\section{Carling 2002}

J. Carling, 'Migration in the age of involuntary immobility: Theoretical reflections and Cape Verdean experiences', Journal of Ethnic and Migration Studies (28) 2002, afl. 1, p. 5-42.

\section{Castles 2007}

S. Castles, 'The migration-asylum nexus and regional approaches', in: S. Kneebone \& F. RawlingsSanaei (red.), New regionalism and asylum seekers. Challenges ahead, Londen: Berghahn Books 2007, p. 25-42. 


\section{De Clerck 2015}

H.M.L. De Clerck, 'Europe is no longer the only "El Dorado" for sub-Saharan Africans: The case of contemporary Senegalese migration to Turkey', Migration and Development, 2015, DOI: 10.1080/21632324.2015.1022086.

\section{Crépeau 2015}

F. Crépeau, 'Europe should make "mobility" central in migration policy, UN rights expert says', $U N$ News Centre 16 juni 2015. Te raadplegen op: www.un.org/ apps/news/story.asp?NewsID= 51163\&utm_content= bufferc2710\&utm_medium = social\&utm_source=facebook. com\&utm_campaign=buffer\#. VYHFsfntmko.

\section{Ferguson 2006}

J. Ferguson, Global shadows. Africa in the neoliberal world order, Durham: Duke World Press 2006.

\section{De Haas 2015}

H. de Haas, 'Laat migratie de vrije loop', NRC Handelsblad 16 mei 2015.

\section{Van Houte \& Den Hertog 2015}

M. van Houte \& L. den Hertog, 'Maak het makkelijker voor migranten om hier te komen', de Volkskrant 29 mei 2015. Te raadplegen op: www.volkskrant.nl/ opinie/maak-het-makkelijkervoor-migranten-om-hier-tekomen a4042236/.

\section{Van Houtum 2015}

H. van Houtum, 'EU-aanpak bootvluchtelingen gaat niet werken', RTL Nieuws 24 april 2015. Te raadplegen op: www.rtlxl.nl/ \#!/rtl-nieuws-132237/5187c77d -01b3-4186-8094-c1ba88731804.

\section{Khosravi 2011}

S. Khosravi, 'Illegal traveller'. An auto-ethnography of borders, New York: Palgrave Macmillan 2011.

\section{Van Liempt 2007}

I. van Liempt Navigating borders: Inside perspectives on the process of human smuggling (PhD thesis), Amsterdam: Amsterdam University Press 2007.

\section{Lucht 2012}

H. Lucht, Darkness before daybreak. African migrants living on the margins in southern Italy today, Berkeley: University of California Press 2012.

\section{Nyberg-Sørensen 2012}

N. Nyberg-Sørenson, 'Revisiting the migration-development nexus: From social networks and remittances to markets for migration control', International Migration (50) 2012, afl. 3, p. 61-76.

\section{Papadopoulou 2005}

A. Papadopoulou, Exploring the asylum-migration nexus: A case study of transit migrants in Europe (Global Migration Perspectives No. 23), Genève: GCIM 2005. 


\section{Van Raaij 2015}

B. van Raaij, 'Het probleem is degelijk op te lossen', de Volkskrant 20 april 2015.

\section{Rumford 2006}

C. Rumford, 'Rethinking European spaces: Territory, borders, governance', Comparative European Politics (4) 2006, afl. 2,

p. 127-140.

\section{Schapendonk 2014}

J. Schapendonk, 'What if networks move? Dynamic social networking in the context of African migration to Europe', Population, Space and Place, 2014, DOI: 10.1002/psp.1860.

\section{Schapendonk \& Steel 2014}

J. Schapendonk \& G. Steel, 'Following migrant trajectories: The $\mathrm{im} / \mathrm{mobility}$ of sub-Saharan Africans en route to the European Union', Annals of the Association of American Geographers (104) 2014, afl. 2, p. 262-270.

\section{Schuster 2005}

L. Schuster, 'The continuing mobility of migrants in Italy: Shifting between places and statuses', Journal of Ethnic and Migration Studies (31) 2005, afl. 4, p. 757-774.

\section{Spijkerboer 2015}

Th. Spijkerboer, 'Bombarderen smokkelboten is niet de oplossing', Nieuwsuur 11 mei 2015. Te raadplegen op: http://nos.nl/ nieuwsuur/artikel/2035157artikel.html?title=bombarderensmokkelboten-is-niet-deoplossing.

\section{Süter 2012}

B. Süter, Tales of transit: SubSaharan African migrants' experiences in Istanbul $(\mathrm{PhD}$ thesis Linköping), Linköping University 2012.

\section{Triulzi \& McKenzie 2013}

A. Triulzi \& R.L. McKenzie, Long journeys. African migrants on the road, Leiden: Brill 2013. 